\title{
Body mass index is associated with the development of acute respiratory distress syndrome
}

\author{
M N Gong, ${ }^{1}$ E K Bajwa, ${ }^{2}$ B T Thompson, ${ }^{2}$ D C Christiani ${ }^{3}$
}

\begin{abstract}
- Additional tables are published online only at http:// thorax.bmj.com/content/vol65/ issue1

${ }^{1}$ Division of Critical Care Medicine, Department of Medicine, Montefiore Medical Center, Bronx, New York, USA; ${ }^{2}$ Pulmonary and Critical Care Unit, Department of Medicine, Massachusetts General Hospital, Harvard Medical School, Boston, Massachusetts, USA; ${ }^{3}$ Environmental Health Department (Environmental and Occupational Medicine and Epidemiology Program), Harvard School of Public Health, Boston, Massachusetts, USA
\end{abstract}

Correspondence to: Dr D C Christiani, Harvard School of Public Health, 665 Huntington Avenue, Boston, MA 02115,

USA; dchris@hsph.harvard.edu

Received 6 April 2009 Accepted 14 August 2009

Published Online First

21 September 2009
ABSTRACT

Background: The relationship between body mass index (BMI) and development of acute respiratory distress syndrome (ARDS) is unknown.

Methods: A cohort study of critically ill patients at risk for ARDS was carried out. BMI was calculated from admission height and weight. Patients were screened daily for AECC (American European Consensus Committee)-defined ARDS and 60-day ARDS mortality.

Results: Of 1795 patients, 83 (5\%) patients were underweight (BMl $<18.5 \mathrm{~kg} / \mathrm{m}^{2}$ ), 627 (35\%) normal (BMl 18.5-24.9), 605 (34\%) overweight (BMI 25-29.9), 364 (20\%) obese (BMI 30-39.9) and $116(6 \%)$ severely obese $(\mathrm{BMI} \geqslant 40)$. Increasing weight was associated with younger age $(p<0.001)$, diabetes $(p<0.0001)$, higher blood glucose $(p<0.0001)$, lower prevalence of direct pulmonary injury $(p<0.0001)$ and later development of ARDS $(p=0.01)$. BMI was associated with ARDS on multivariate analysis $\left(\mathrm{OR}_{\mathrm{adj}} 1.24\right.$ per SD increase; $95 \% \mathrm{Cl}$ 1.11 to 1.39$)$. Similarly, obesity was associated with ARDS compared with normal weight $\left(\mathrm{OR}_{\mathrm{adj}} 1.66 ; 95 \% \mathrm{Cl}\right.$ 1.21 to 2.28 for obese; $\mathrm{OR}_{\text {adj }} 1.78 ; 95 \% \mathrm{Cl} 1.12$ to 2.92 for severely obese). Exploratory analysis in a subgroup of intubated patients without ARDS on admission $(n=1045)$ found that obese patients received higher peak $(p<0.0001)$ and positive end-expiratory pressures $(p<0.0001)$ than non-obese patients. Among patients with ARDS, increasing BMI was associated with increased length of stay ( $p=0.007)$ but not with mortality $\left(\mathrm{OR}_{\mathrm{adj}} 0.89\right.$ per SD increase; $95 \% \mathrm{Cl} 0.71$ to 1.12).

Conclusion: BMI was associated with increased risk of ARDS in a weight-dependent manner and with increased length of stay, but not with mortality. Additional studies are needed to determine whether differences in initial ventilator settings may contribute to ARDS development in the obese.

Obesity is considered to be an epidemic. In the last 20 years, obesity has tripled in the UK. ${ }^{1}$ In the USA, the estimated mortality attributed to obesity is $>110000$ a year, with healthcare costs estimated at $5.7 \%$ of the national health expenditures. ${ }^{2}$ The most expensive component of healthcare delivery is critical care. ${ }^{3}$ Although obesity has been associated with increased mortality in trauma, obesity's impact on other critical illnesses is less clear. ${ }^{45}$ Some investigators found obesity to be associated with increased mortality, increased complications and length of hospital stay. ${ }^{67}$ Other studies showed no to improved mortality in the obese patients. ${ }^{8-10}$

Acute respiratory distress syndrome (ARDS) is now known to be associated with high mortality and high healthcare costs. ${ }^{11}$ Most studies of obesity and ARDS have focused on mortality, with some indicating no association and others reporting lower mortality among the obese. ${ }^{812}$ Little is known about whether body weight and obesity are associated with a variable increased risk of developing lung injury. With the rising incidence of obesity and the increased mortality, morbidity and health expenditures associated with ARDS, it is important to understand how body mass index (BMI) and obesity may relate to the development of ARDS in order to care for the growing number of obese patients seen in the ICU and to plan for future epidemiological and clinical studies of ARDS.

In a cohort of critically ill patients enrolled in the Molecular Epidemiology of ARDS study, we aimed to determine if BMI and obesity are associated with development of ARDS and mortality in ARDS.

\section{MATERIALS AND METHODS}

\section{Study population}

All subjects in this study were enrolled into the Molecular Epidemiology of ARDS study, as described previously. ${ }^{13}$ Briefly, all admissions to adult intensive care units (ICUs) were eligible for the study if they were admitted with one or more study-defined risk factor for ARDS and no exclusion criteria (Supplementary Table S1 online). The study was conducted at the Massachusetts General Hospital (MGH) since 1999 and at the Beth Israel Deaconess Medical Center (BIDMC) (Boston, Massachusetts) since 2007. Incidences of ARDS and mortality in ARDS did not differ between the two sites $(p \geqslant 0.7)$. The Human Subjects Committees of the MGH, BIDMC and Harvard School of Public Health approved the study, and informed consent was obtained from all subjects or their surrogates.

BMI was calculated from height and weight recorded on admission to the ICU (BMI = weight $\left.(\mathrm{kg}) / \mathrm{ht}(\mathrm{m})^{2}\right)$. Patients without height and weight recorded including those for whom height could not be determined (bilateral amputees, severe kyphoscoliosis or contractures) were excluded.

Research coordinators screened all patients daily for ARDS defined similarly to the American European Consensus Committee (AECC): (1) hypoxaemic respiratory failure requiring intubation and $\mathrm{PaO}_{2} / \mathrm{FiO}_{2} \leqslant 200 \mathrm{~mm} \mathrm{Hg}$; (2) the presence of bilateral infiltrates on chest radiographs; and (3) pulmonary arterial occlusion pressure $\leqslant 18 \mathrm{~mm} \mathrm{Hg}$ or no suspicion for congestive heart failure. Infiltrates on chest radiographs were defined as opacities consistent with ARDS that could not be explained completely by pleural 
effusions, mass, body habitus or atelectasis. Daily chest radiographs were reviewed by two physicians. Any disagreement went to a third physician for arbitration. All physicians underwent a consensus training session on the radiological criteria for ARDS. All were blinded to the clinical status of the patients and the presence of other ARDS criteria. The agreement between interpreters was good and similar to prior reports (Kappa 0.75 (95\% CI 0.60 to 0.90$)){ }^{14}$

Patients with ARDS were followed for all-cause 60-day mortality, ICU and hospital length of stay, daily organ dysfunction score (MODS) and ventilator-free days, as previously described. ${ }^{15}$

\section{Statistical analysis}

Univariate analyses were performed with $\chi^{2}$ tests and Wilcoxon rank sum or analysis of variance (ANOVA), as appropriate. We explored the relationship between BMI and the development of ARDS and mortality in ARDS in two ways. We included BMI as a continuous variable in a logistic regression model after determining that the logit was linear. Odds ratios (ORs) were calculated per $1 \mathrm{SD}$ increase in predictor variables. We also categorised BMI according to the National Institutes of Health (NIH) definition of obesity ${ }^{16}$ (fig 1) and reported the ORs using normal weight as the reference. Categorising the BMI according to quartiles yielded nearly identical results so the NIH definition was used as it was more clinically relevant.

Final multivariate models included variables related to weight from univariate analyses $(p<0.05)$, and factors previously reported to be associated with ARDS such as transfusion of packed red cells and haematological failure with platelets $<80 \times 10^{9} / 1$ or factors associated with ARDS mortality such as high tidal volume ventilation, chronic liver disease and transfusion. ${ }^{13}$ To account for secular changes in the development and outcomes in ARDS, conditional logistic regression was used after stratifying by calendar year of study. Continuous variables were included as linear if the plot of the logit was linear, and categorised if not (tidal volume/ideal body weight (IBW) and positive end expiratory pressure (PEEP)). Glucose was log transformed prior to inclusion in the model. No colinearity was found after calculating the condition index
$(<2.2)$ and variance inflation index $(<1.6)$. Interactions between BMI and other covariates in the model were tested with an interaction term and none was found $(p>0.1)$. Any $p$ values $\leqslant 0.05$ were considered statistically significant. Daily Multiple Organ Dysfunction Score (MODS) after ARDS was compared employing mixed-effects models using the Proc Mixed procedure. All analyses were conducted using SAS v9.

\section{RESULTS}

Between 9 September 1999 and 4 August 2007, 1995 patients were enrolled in the Molecular Epidemiology of ARDS study. BMI data were missing from 200 subjects (10\%). Compared with subjects with BMI data, those missing BMI data tended to be slightly younger (mean (SD) 59 (20) vs 61 (18) years; $p=0.06)$. They had a lower prevalence of septic shock $(p=0.002)$, lower APACHE III (Acute Physiology and Chronic Health Evaluation III) scores $(p<0.0001)$, less respiratory failure $(p=0.0004)$ and a lower rate of ARDS $(p<0.0001)$. There was no difference in gender $(p>0.9)$, site of enrolment $(p>0.07)$, diabetes $(p>0.9)$ or peak glucoses after ICU admission $(p=0.2)$. The 1795 patients with BMI data were analysed (fig 1).

The mean BMI in the subjects was $27.9(8.1) \mathrm{kg} / \mathrm{m}^{2}$. A total of $547(30 \%)$ subjects developed ARDS. At baseline, obese patients tended to be younger and were less likely to have a direct pulmonary injury (such as pneumonia) as the predisposing risk for ARDS but had a higher likelihood of requiring intubation (table 1). The highest glucose on ICU admission and the proportion of patients with diabetes increased with obesity. The proportion of patients who are female varied significantly with weight but there was no difference between weight categories in race, APACHE III physiology score, septic shock and comorbidities such as cancer, chronic liver disease and renal failure.

\section{Development of ARDS}

Patients with ARDS had a higher BMI compared with patients who did not develop ARDS (28.5 (9.1) kg/m² vs 27.6 (7.7) kg/ $\left.\mathrm{m}^{2} ; \mathrm{p}=0.03\right)$. Development of ARDS increased significantly with increasing weight (fig 2A) but the timing of ARDS development differed by weight. The number of days between

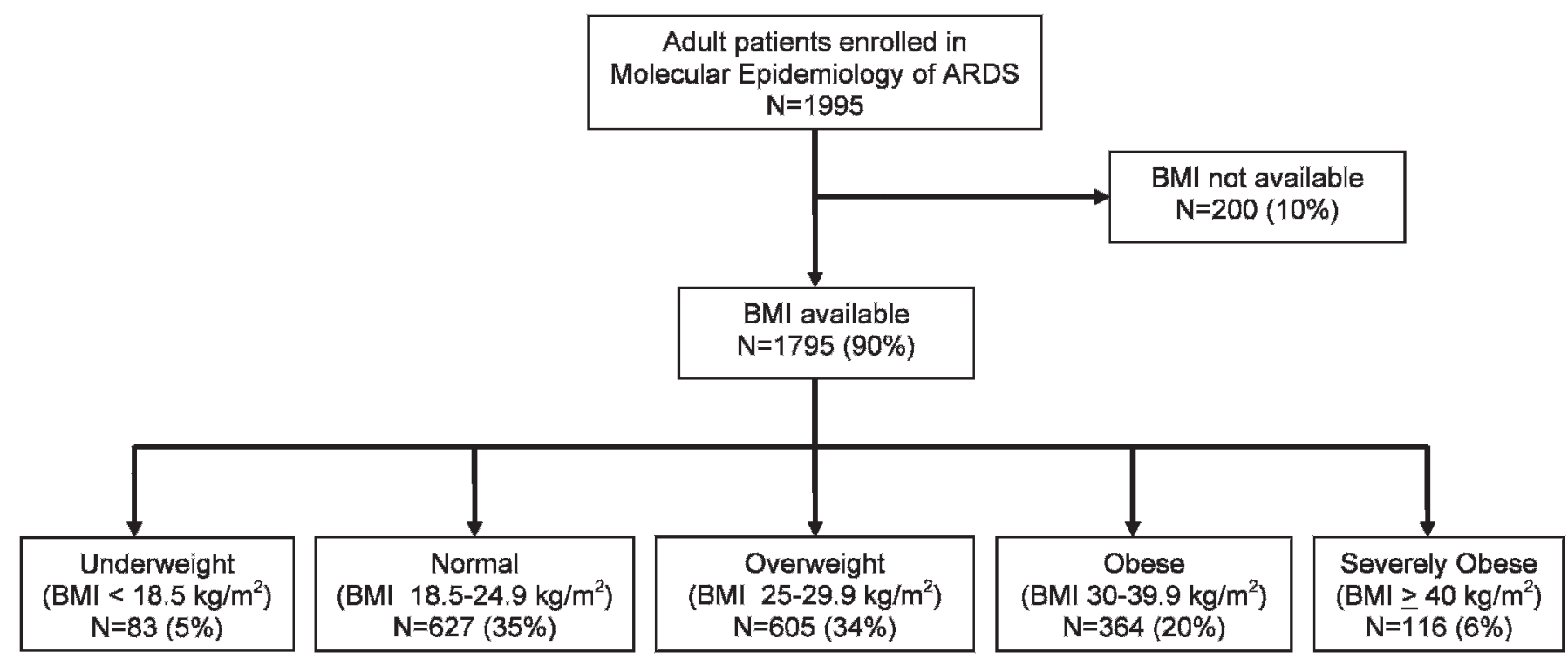

Figure 1 Breakdown of patients by weight in the Molecular Epidemiology of ARDS cohort. ARDS, adult respiratory distress syndrome; BMI, body mass index. 
Table 1 Clinical risk for ARDS and baseline characteristics by BMI categories*

\begin{tabular}{|c|c|c|c|c|c|c|}
\hline Baseline characteristics & $\begin{array}{l}\text { Underweight } \\
(\mathrm{n}=\mathbf{8 3})\end{array}$ & $\begin{array}{l}\text { Normal } \\
(\mathrm{n}=627)\end{array}$ & $\begin{array}{l}\text { Overweight } \\
(\mathrm{n}=605)\end{array}$ & $\begin{array}{l}\text { Obese } \\
(n=364)\end{array}$ & $\begin{array}{l}\text { Severely } \\
\text { obese } \\
(n=116)\end{array}$ & p Value \\
\hline \multicolumn{7}{|l|}{ Clinical risk for ARDS, n (\%) } \\
\hline Sepsis syndrome & $29(35 \%)$ & 212 (34\%) & $200(33 \%)$ & $112(31 \%)$ & $41(35 \%)$ & 0.8 \\
\hline Pneumonia source & $23(28 \%)$ & $134(21 \%)$ & $110(18 \%)$ & $71(20 \%)$ & $22(19 \%)$ & 0.07 \\
\hline Extrapulmonary source & $6(7 \%)$ & $78(13 \%)$ & $90(15 \%)$ & $41(11 \%)$ & $19(16 \%)$ & \\
\hline Septic shock & 47 (57\%) & $310(49 \%)$ & $282(47 \%)$ & $186(51 \%)$ & 61 (53\%) & 0.3 \\
\hline Pneumonia source & $32(39 \%)$ & $188(30 \%)$ & $168(27 \%)$ & $85(23 \%)$ & $30(26 \%)$ & 0.003 \\
\hline Extrapulmonary source & $15(18 \%)$ & $122(19 \%)$ & $114(19 \%)$ & $101(28 \%)$ & $31(27 \%)$ & \\
\hline Trauma & $3(4 \%)$ & $41(7 \%)$ & $63(10 \%)$ & $27(7 \%)$ & $8(7 \%)$ & 0.06 \\
\hline Massive transfusion & $4(5 \%)$ & $68(11 \%)$ & $69(11 \%)$ & $46(13 \%)$ & $9(8 \%)$ & 0.2 \\
\hline Aspiration & $7(8 \%)$ & $65(10 \%)$ & $56(9 \%)$ & $33(9 \%)$ & $4(3 \%)$ & 0.2 \\
\hline Direct pulmonary injury & $58(70 \%)$ & $367(59 \%)$ & $342(57 \%)$ & $181(50 \%)$ & $55(47 \%)$ & $<0.0001$ \\
\hline$>1$ risk for ARDS & $8(10 \%)$ & $77(12 \%)$ & $75(12 \%)$ & $46(13 \%)$ & $9(8 \%)$ & 0.6 \\
\hline Age (mean (SD)), years & $61(20)$ & $63(18)$ & $62(17)$ & $60(17)$ & $54(14)$ & $<0.0001$ \\
\hline Female gender, $\mathrm{n}(\%)$ & $48(58 \%)$ & $234(37 \%)$ & $184(30 \%)$ & $155(43 \%)$ & $58(50 \%)$ & $<0.0001$ \\
\hline Caucasians, n (\%) & 78 (94\%) & $576(92 \%)$ & $557(92 \%)$ & $330(91 \%)$ & $110(95 \%)$ & 0.6 \\
\hline \multicolumn{7}{|l|}{ Co-morbid conditions, n (\%) } \\
\hline Diabetes & $14(17 \%)$ & $113(18 \%)$ & $144(24 \%)$ & $140(38 \%)$ & $52(45 \%)$ & $<0.0001$ \\
\hline Chronic liver disease & $3(4 \%)$ & $40(6 \%)$ & $31(5 \%)$ & $17(5 \%)$ & $8(7 \%)$ & 0.6 \\
\hline End-stage renal disease & $4(5 \%)$ & $38(6 \%)$ & $35(6 \%)$ & $27(7 \%)$ & $11(9 \%)$ & 0.5 \\
\hline History of alcohol abuse & $8(10 \%)$ & $81(13 \%)$ & $77(13 \%)$ & $33(9 \%)$ & $9(8 \%)$ & 0.2 \\
\hline Metastatic cancer & $1(1 \%)$ & $26(4 \%)$ & $14(2 \%)$ & $9(2 \%)$ & $3(3 \%)$ & 0.3 \\
\hline $\begin{array}{l}\text { Corticosteroid use prior to ICU } \\
\text { admission }\end{array}$ & $5(6 \%)$ & $67(11 \%)$ & $40(7 \%)$ & $35(10 \%)$ & $14(12 \%)$ & 0.07 \\
\hline \multicolumn{7}{|l|}{ Severity of illness on ICU admission } \\
\hline $\begin{array}{l}\text { APACHE physiology score (mean } \\
\text { (SD)) }\end{array}$ & $59(18)$ & $57(21)$ & $57(22)$ & $57(20)$ & $58(22)$ & 0.9 \\
\hline $\begin{array}{l}\text { APACHE III total score (mean } \\
\text { (SD)) }\end{array}$ & $70(22)$ & $70(23)$ & $69(24)$ & $68(22)$ & $67(25)$ & 0.07 \\
\hline $\begin{array}{l}\text { Highest glucose within } 24 \mathrm{~h} \text { after } \\
\text { ICU admission (median } 25-75 \% \text { ) }\end{array}$ & $173(131-228)$ & $172(138-228)$ & $183(148-240)$ & $190(149-250)$ & $195(155-257)$ & $<0.0001$ \\
\hline $\begin{array}{l}\text { Haematological failure (platelets } \\
\left.<80 \times 10^{9} / 1\right), \mathrm{n}(\%)\end{array}$ & $13(16 \%)$ & $96(15 \%)$ & $113(19 \%)$ & $49(13 \%)$ & $11(9 \%)$ & 0.06 \\
\hline Systolic BP $<90$ mm Hg, n (\%) & $63(76 \%)$ & $452(72 \%)$ & $420(69 \%)$ & $248(68 \%)$ & $76(66 \%)$ & 0.3 \\
\hline $\begin{array}{l}\text { Acute respiratory failure } \\
\text { requiring intubation, } \mathrm{n}(\%)\end{array}$ & $51(61 \%)$ & $421(67 \%)$ & $442(73 \%)$ & $266(73 \%)$ & $80(69 \%)$ & $<0.05$ \\
\hline Transfusion of PRBCs, $n(\%)$ & $38(46 \%)$ & $337(54 \%)$ & $313(52 \%)$ & $190(52 \%)$ & $57(49 \%)$ & 0.6 \\
\hline ICU mortality, n (\%) & $12(15 \%)$ & $93(15 \%)$ & $80(13 \%)$ & $49(14 \%)$ & $21(18 \%)$ & 0.7 \\
\hline $\begin{array}{l}\text { Days from ICU admission to } \\
\text { fulfilment of ARDS criteria among } \\
\text { those who develop ARDS* (mean } \\
\text { (SD)) }\end{array}$ & $0.55(1.06)$ & $1.9(3.0)$ & $2.5(4.1)$ & $2.5(4.4)$ & $2.8(4.1)$ & 0.01 \\
\hline
\end{tabular}

${ }^{*}$ Only calculated for patients with ARDS in each weight category.

APACHE, Acute Physiology and Chronic Health Evaluation; ARDS, acute respiratory distress syndrome; BP, blood pressure; ICU, intensive care unit; PRBCs, packed red blood cells.

ICU admission and development of ARDS increased with increasing weight (table 1), suggesting that obese patients with ARDS develop it later in the course of their ICU hospitalisation. Increasing BMI was associated with ARDS on univariate $\left(\mathrm{OR}_{\mathrm{adj}}\right.$ 1.11 per SD increase in BMI; 95\% CI 1.01 to 1.22) and multivariate analysis $\left(\mathrm{OR}_{\text {adj }} 1.24\right.$ per SD increase $95 \%$ CI 1.11 to 1.39) (table 2). After categorising BMI into NIH-defined weight categories, there were increasing odds of ARDS with increasing obesity compared with normal weight individuals (fig 3A). Excluding transfer patients and patients with liver disease whose BMI may be distorted by fluids prior to transfer or by ascities, the association between BMI and increased ARDS remained ( $O R_{a d j} 1.19$ per SD increase; 95\% CI 1.03 to 1.37 ). Excluding underweight patients did not significantly change the results $\left(\mathrm{OR}_{\mathrm{adj}} 1.21\right.$ per SD increase; $95 \% \mathrm{CI} 1.08$ to 1.36$)$.

We explored whether the body habitus of the obese and severely obese patients may make it more likely that they would meet the respiratory failure or the radiographic criteria of ARDS.
Obese patients (BMI $\geqslant 30 \mathrm{~kg} / \mathrm{m}^{2}$ ) were more likely to have hypoxaemic respiratory failure than non-obese patients (BMI $<30 \mathrm{~kg} / \mathrm{m}^{2}$ ) (table 3). However, obese patients were not more likely to have bilateral infiltrates on chest radiograph than nonobese patients. In addition, heart failure was also less likely to be excluded in the obese. The body habitus of the severely obese may complicate the diagnosis of ARDS the most. Yet after excluding the severely obese, the association between obesity and ARDS was actually strengthened $\left(\mathrm{OR}_{\mathrm{adj}} 1.40\right.$ per $\mathrm{SD}$ increase in BMI; 95\% CI 1.17 to 1.68 ; OR adj $1.72,95 \%$ CI 1.25 to 2.36 for obese vs normal weight). The misclassification of ARDS from atelectasis or body habitus might be expected to result in a lower attributable mortality from ARDS among the obese. Yet, ICU mortality was consistently higher in ARDS compared with patients without ARDS among all weight groups $(45 \%(9 / 20)$ vs $5 \%$ (3/60), $p=0.0001$ among the underweight patients; $32 \%(54 / 171)$ vs $9 \%$ (39/448), $p<0.0001$ in the normal weight; $31 \%(56 / 181)$ vs $6 \%(24 / 418), p<0.0001$ 
Figure 2 (A) Development of acute respiratory distress syndrome (ARDS) ARDS by body mass index category. $p$ Values are for Cochran-Armitage trend test. and (B) 60-day mortality after developing
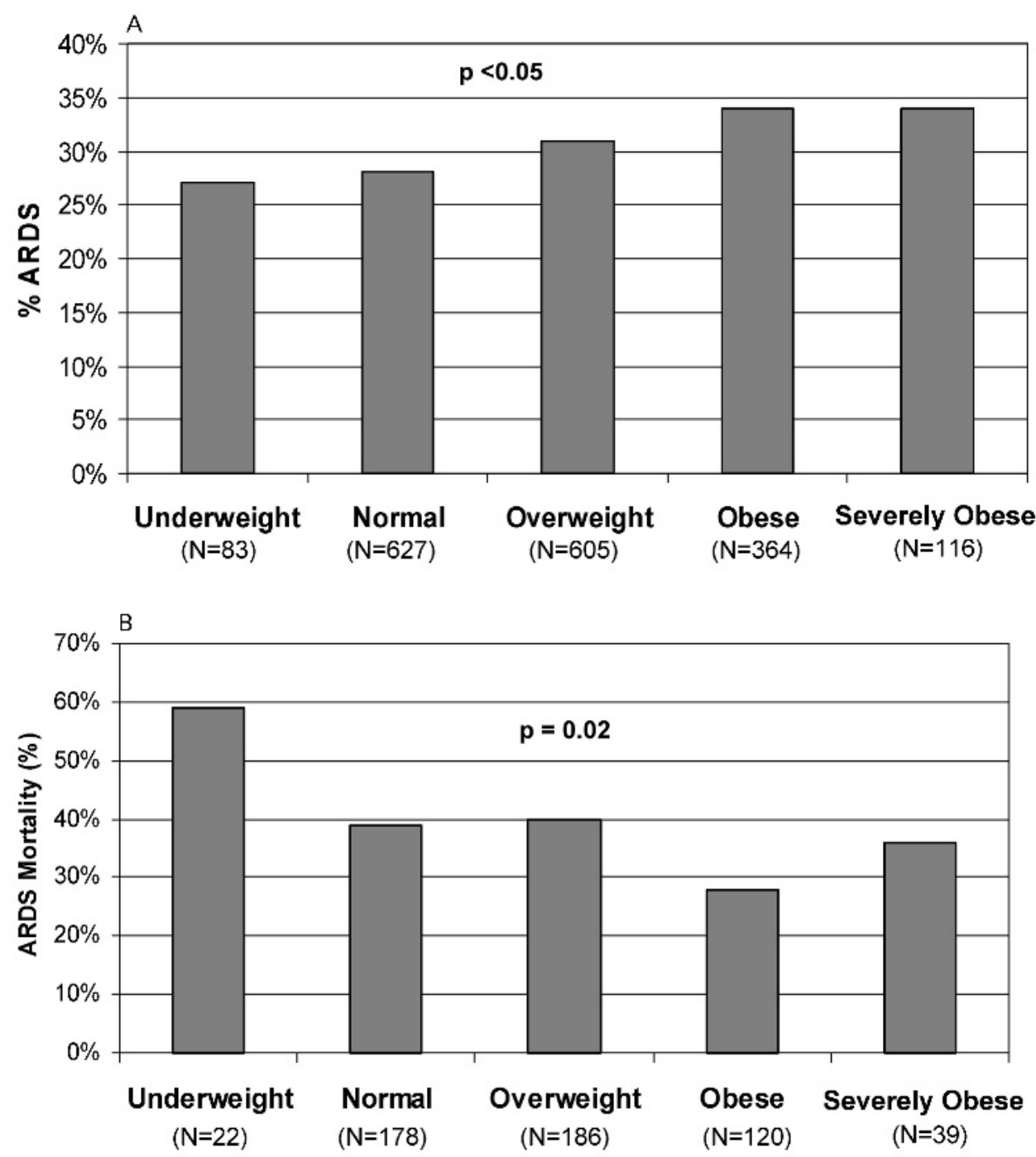

among the overweight; $26 \%(30 / 117)$ vs $8 \% \quad(19 / 241)$, $p=0.0001$ among the obese; and $33 \%(13 / 39)$ vs $11 \%$ (8/ 76), $p=0.005$ in the severely obese).

To investigate why obese patients may be more likely to develop ARDS especially later in their ICU course, we examined the role of initial ventilatory parameters on ARDS development in the subgroup of 1045 patients (58\% of cohort) who were intubated but who did not fulfil the criteria for ARDS during the first day of their ICU admission (table 4). Increasing weight category was associated with higher tidal volumes, peak inspiratory pressures (PIPs) and PEEPs on ICU admission. On multivariate analyses, higher PEEP and PIP after ICU admission remained significantly associated with increased development of ARDS (Supplementary Table S2 online). BMI was associated with increased development of ARDS but the statistical significance was now borderline in this subgroup of intubated patients $\left(\mathrm{OR}_{\mathrm{adj}} 1.19\right.$ per SD increase, $95 \%$ CI 0.99 to 1.43 ; $\mathrm{p}=0.06)$.

\section{Outcomes in ARDS}

The 60-day ARDS mortality was 37\%. ARDS survivors had higher BMI than non-survivors $(29.2$ (10.1) vs 27.2 (6.9); $\mathrm{p}=0.01$ ), but this may be due in part to the higher mortality in the underweight patients (fig 2B). On multivariate analyses after adjusting for age, APACHE III, other variables associated with weight on univariate analyses and previously found predictors for ARDS mortality such as chronic liver disease, transfusion of red cells and high tidal volume ventilation $(>8 \mathrm{ml} /$ kg IBW), BMI was no longer associated with ARDS mortality $\left(\mathrm{OR}_{\mathrm{adj}} 0.89\right.$ per SD increase, $95 \% \mathrm{CI} 0.71$ to 1.12$)$ (fig $\left.3 \mathrm{~B}\right)$. Excluding underweight patients did not change the findings.

BMI was not significantly associated with ICU mortality (OR 0.86 per SD increase, $95 \%$ CI 0.72 to 1.04 ). After categorising by the NIH definition of obesity, obesity was associated with significantly longer ICU and hospital length of stay but was not associated with ICU mortality or ventilator-free days (table 5), and organ dysfunction after ARDS did not vary significantly between weight categories $(p=0.4)$.

\section{DISCUSSION}

In a cohort of ICU patients at risk for ARDS, we found significant associations between BMI and obesity and increased development of ARDS that persist even after accounting for known risk factors for the development of ARDS. While obesity was found to be associated with increased ICU and hospital length of stay, there was no significant association between obesity and ARDS mortality after adjusting for potential predictors of mortality. 
Table 2 Predictors for development of ARDS on multivariate analysis

\begin{tabular}{|c|c|c|}
\hline & OR $(95 \% \mathrm{Cl})$ & p Value \\
\hline Age (per SD) & 0.75 (0.66 to 0.84$)$ & $<0.0001$ \\
\hline Female & $1.11(0.88$ to 1.39$)$ & 0.4 \\
\hline $\begin{array}{l}\text { Apache III score* (per SD } \\
\text { increase) }\end{array}$ & $1.26(1.10$ to 1.44$)$ & 0.0009 \\
\hline Diabetes & $0.62(0.46$ to 0.83$)$ & 0.001 \\
\hline \multicolumn{3}{|l|}{ Clinical risk for ARDS } \\
\hline Septic shock & $1.70(1.33$ to 2.18$)$ & $<0.0001$ \\
\hline Direct pulmonary injury & $3.29(2.57$ to 4.21$)$ & $<0.0001$ \\
\hline $\begin{array}{l}\text { Haematological failure (platelets } \\
<80 \times 10^{9} / \text { ) }\end{array}$ & 1.59 (1.17 to 2.17$)$ & 0.003 \\
\hline Transfusion of red blood cells & $1.47(1.16$ to 1.85$)$ & 0.001 \\
\hline Intubated on ICU admission & $2.44(1.84$ to 3.25$)$ & $<0.0001$ \\
\hline $\begin{array}{l}\text { Peak plasma glucose in first } 24 \mathrm{~h} \\
\text { after ICU admission (per unit } \\
\text { increase) }\end{array}$ & $1.08(0.78$ to 1.49$)$ & 0.7 \\
\hline $\begin{array}{l}\text { Body mass index (per SD } \\
\text { increase) }\end{array}$ & $1.24(1.11$ to 1.39$)$ & 0.0001 \\
\hline
\end{tabular}

${ }^{*}$ APACHE III score calculated without the $\mathrm{PaO}_{2} / \mathrm{FiO}_{2}$ score.

APACHE, Acute Physiology and Chronic Health Evaluation; ARDS, acute respiratory distress syndrome; ICU, intensive care unit.

This study has a number of strengths. First, most studies on obesity and acute lung injury (ALI)/ARDS have focused on mortality as the outcome rather than development of ALI/ ARDS. This is a large cohort specifically designed to examine the development of ARDS. Thus, the diagnosis of ARDS was carefully carried out with daily screening for ARDS criteria and consensus reading of chest radiographs after uniform training with blinding of reviewers. Important predictors for the development of ARDS were available for analyses. Lastly, BMI was available for the majority of patients in the cohort $(90 \%)$, allowing for all weight categories to be available for analyses.

There have been few studies that have examined obesity and development of ARDS, and the results have been conflicting. ${ }^{67}{ }^{17}$ Interpretation of these results is difficult as ARDS was not their primary outcome so it is unclear to what extent misclassification and underdiagnoses of ARDS may have occurred. Consistent with our findings, another study found that a higher BMI was associated with primary graft dysfunction, a form of ARDS that develops after lung transplant. ${ }^{18}$

It is possible that obese patients may more easily fulfil AECC criteria for ARDS because of their body habitus, which may increase the likelihood of respiratory failure and make interpretation of chest radiographs difficult. However, it is not clear that this completely accounts for the association between obesity and ARDS in this study. Although obese patients in this study were more likely to develop hypoxaemic respiratory failure, they were not more likely to have bilateral infiltrates consistent with ARDS. Our consensus training on radiological findings for ARDS specifically indicates that findings consistent with body habitus should not be interpreted as ARDS. Severely obese patients (BMI $\geqslant 40 \mathrm{~kg} / \mathrm{m}^{2}$ ) are most prone to difficult radiographic interpretation and to obesity-related respiratory failure. Excluding them actually strengthened the association between BMI and ARDS. Lastly, the consistently higher mortality seen in patients with ARDS compared with those without ARDS in every weight category would argue against attributing ARDS to mere body habitus and atelectasis in the obese.

Our study found that the initial ventilatory strategy employed on admission to the ICU prior to development of ARDS varied by weight, and may contribute to development of ARDS in obese patients. Ventilator-induced lung injury is a well
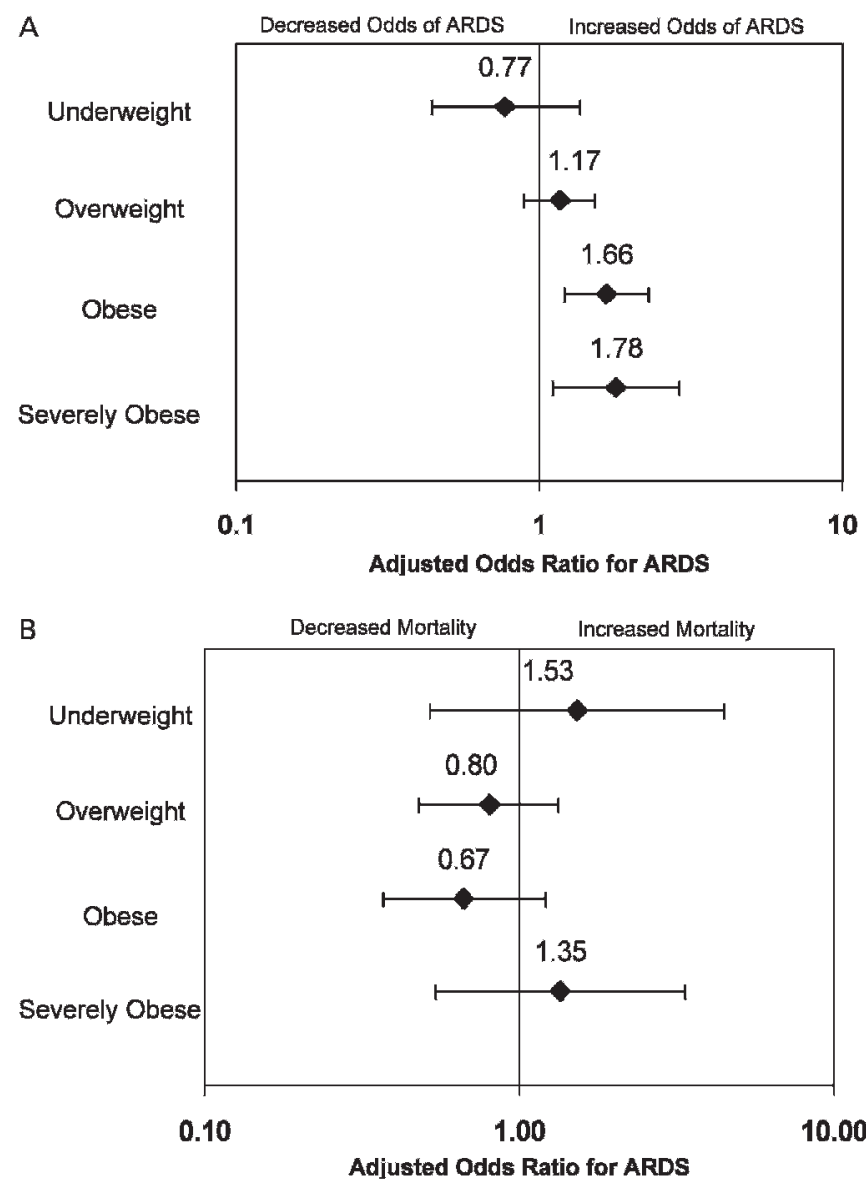

Figure 3 (A) ORs for development of acute respiratory distress syndrome (ARDS) and (B) 60-mortality after developing ARDS by body mass index category. The reference group is patients in the normal weight category. ORs for development of ARDS are stratified by calendar year of study and adjusted for age, gender, APACHE III (Acute Physiology and Chronic Health Evaluation III) score (without the $\mathrm{PaO}_{2} /$ $\mathrm{FiO}_{2}$ score), diabetes, clinical risk for ARDS such as septic shock and direct pulmonary injury, haematological failure, transfusion of packed red blood cells, peak glucose in the first $24 \mathrm{~h}$ of ICU admission and acute respiratory failure on intensive care unit (ICU) admission. ORs for ARDS mortality are stratified by calendar year of study and adjusted for age, gender, APACHE III score, aetiology for ARDS (septic shock or direct pulmonary injury), co-morbidities such as diabetes and chronic liver disease, haematological failure, number of packed red cells transfused, peak glucose in the first $24 \mathrm{~h}$ of ICU admission, and high tidal volume ventilation (>8 ml/kg ideal body weight) on the day ARDS criteria were fulfilled.

Table 3 Proportion of obese (BMl $\left.\geqslant 30 \mathrm{~kg} / \mathrm{m}^{2}\right)$ and non-obese (BMl $<30 \mathrm{~kg} / \mathrm{m}^{2}$ ) patients who fulfilled each ARDS criterion on at least 1 day during their ICU stay

\begin{tabular}{lccc}
\hline & \multicolumn{3}{l}{$\begin{array}{l}\text { Number (\%) of patients who fulfilled criteria on at least one } \\
\text { ICU day }\end{array}$} \\
\cline { 2 - 4 } ARDS criteria & $\begin{array}{l}\mathbf{B M I ~}<\mathbf{3 0} \mathbf{~ k g} / \mathbf{m}^{2} \\
(\mathbf{n}=\mathbf{1 3 1 5})\end{array}$ & $\begin{array}{l}\mathbf{B M I} \geqslant \mathbf{3 0} \mathbf{~ k g} / \mathbf{m}^{\mathbf{2}} \\
(\mathbf{n}=\mathbf{4 8 0})\end{array}$ & $\mathbf{p}$ Value \\
\hline $\begin{array}{l}\text { Intubated with } \\
\mathrm{PaO}_{2} / \mathrm{FiO} \mathrm{O}_{2} \leqslant 200\end{array}$ & $569(43 \%)$ & $249(52 \%)$ & 0.001 \\
$\begin{array}{l}\mathrm{Bilateral} \mathrm{infiltrates} \\
\text { on chest radiograph }\end{array}$ & $764(58 \%)$ & $286(59 \%)$ & 0.6 \\
$\begin{array}{l}\text { Exclusion of left } \\
\text { atrial heart failure }\end{array}$ & $1154(88 \%)$ & $404(84 \%)$ & $<0.05$ \\
\hline
\end{tabular}

ARDS, acute respiratory distress syndrome; BMI, body mass index; ICU, intensive care unit. 
Table 4 Initial ventilatory parameters after ICU admission by weight among the subgroup of 1045 patients who were intubated on mechanical ventilation but did not fulfil the criteria for ARDS on ICU admission

\begin{tabular}{|c|c|c|c|c|c|c|}
\hline Ventilatory parameter on ICU admission & Underweight $(n=35)$ & Normal $(n=349)$ & $\begin{array}{l}\text { Overweight } \\
(\mathrm{n}=374)\end{array}$ & Obese $(n=218)$ & $\begin{array}{l}\text { Severely obese } \\
(n=69)\end{array}$ & p Value \\
\hline Tidal volume* $(\mathrm{ml})$ mean $(\mathrm{SD})$ & $480(135)$ & $595(168)$ & $625(159)$ & $628(312)$ & $614(168)$ & 0.003 \\
\hline \multicolumn{7}{|l|}{$\begin{array}{l}\text { Number of patients (\%) ventilated with tidal } \\
\text { volumes: }\end{array}$} \\
\hline$\leqslant 8 \mathrm{ml} / \mathrm{kg} \mathrm{IBW}$ & $17(49 \%)$ & $121(35 \%)$ & $115(31 \%)$ & $53(24 \%)$ & $27(39 \%)$ & 0.01 \\
\hline $8.1-10 \mathrm{ml} / \mathrm{kg} \mathrm{IBW}$ & $12(34 \%)$ & $103(30 \%)$ & $119(32 \%)$ & $77(35 \%)$ & $10(14 \%)$ & 0.02 \\
\hline Peak pressure $\uparrow\left(\mathrm{cm} \mathrm{H}_{2} \mathrm{O}\right)$ mean $(\mathrm{SD})$ & $22(7.5)$ & $22(6.3)$ & $22(6.9)$ & $24(7.7)$ & $28(8.0)$ & $<0.0001$ \\
\hline $\begin{array}{l}\text { Static total respiratory system compliance: (ml/ } \\
\mathrm{cm} \mathrm{H}_{2} \mathrm{O} \text { ) mean (SD) }\end{array}$ & $28(6.7)$ & $34(12)$ & $38(23)$ & $34(13)$ & $36(22)$ & 0.5 \\
\hline PEEP§ $\left(\mathrm{cm} \mathrm{H}_{2} \mathrm{O}\right)$ mean (SD) & $5.6(1.6)$ & $6.4(2.6)$ & $6.6(2.5)$ & $6.7(2.8)$ & $8.5(4.1)$ & $<0.0001$ \\
\hline \multicolumn{7}{|l|}{ Number of patients (\%) ventilated with PEEP: } \\
\hline$\leqslant 5 \mathrm{~cm} \mathrm{H}_{2} \mathrm{O}$ & $29(83 \%)$ & $238(68 \%)$ & $229(61 \%)$ & $137(63 \%)$ & $27(39 \%)$ & $<0.0001$ \\
\hline
\end{tabular}

*Tidal volumes missing in 10 normal, 9 overweight, 5 obese and 2 severely obese patients.

†Peak pressure not available in 15 underweight, 112 normal, 117 overweight, 78 obese and 20 severely obese patients.

\$Compliance (tidal volume/(static plateau pressure - PEEP)) not available in 21 underweight, 171 normal, 170 overweight, 78 obese and 32 severely obese patients.

$\S$ Not available in 5 normal, 3 overweight and 2 obese patients.

ARDS, acute respiratory distress syndrome; IBW, ideal body weight; ICU, intensive care unit; PEEP, positive end expiratory pressure.

recognised model of ALI/ARDS. ${ }^{19}$ Recently, several studies have found that high PIP, increasing PEEP and larger tidal volumes were all associated with increased development of ARDS later in the ICU stay. ${ }^{20}$ Examining patients with ALI enrolled in ARDSnet trials, O'Brien et al found that obese patients had significantly higher tidal volumes and peak airway pressures prior to enrolment than normal weight patients. ${ }^{12}$ However, because PIP, tidal volume or PEEP was not available for onethird of intubated patients $(n=354)$, the loss of statistical significance between BMI and ARDS may be due to the loss of statistical power and the results should be considered exploratory. Nevertheless, these findings suggest that obese patients may be more frequently ventilated with injurious settings. ${ }^{21} 22$

However, initial ventilatory settings may not completely explain the association between obesity and ARDS. Alternative mechanisms are possible. Obesity has been associated with increased risk for infections and infectious complications. ${ }^{23}$ Obesity may promote viral pneumonia and ARDS, as suggested by a recent CDC (Centers for Disease Control) report on H1N1 infection. ${ }^{24}$ Of 10 patients with $\mathrm{H} 1 \mathrm{~N} 1$ with refractory ARDS in Michigan, 9 were obese and 7 were severely obese. Autopsy reveals viral pneumonitis and diffuse alveolar damage. Alternatively, aspiration may play a role. Although aspiration was not more frequent among obese patients on ICU admission in this study, obese patients, who have greater incidence of difficult intubations and complications from intubations, ${ }^{25}$ may be more likely to have aspirated after ICU admission which may further influence their risk for developing ARDS. In addition, obesity has been found to promote the inflammatory response and endothelial changes commonly seen in ARDS. ${ }^{26}{ }^{27}$ Elevated levels of inflammatory adipokines are found in obesity, and two adipokines, pre-B cell-enhancing factor (PBEF) and leptin, have been associated with development of ARDS in animal and clinical studies. ${ }^{28-31}$ In addition, obese patients are often treated with medications such as ACE inhibitors and statins, although animal models suggest that these agents protect against development of lung injury. ${ }^{32} 33$

Our results on BMI and ARDS mortality are consistent with previous observations. Similar to O'Brien et al and the Kings County cohort, we found a U-shaped distribution in risk for ARDS mortality, and increased ICU and hospital length of stay in the obese and severely obese patients with ARDS. ${ }^{89}$ Other studies that did not focus on ARDS have found that obese, critically ill patients have increased length of stay with either unchanged or improved mortality. ${ }^{4} 103435$

There are several limitations to this study. We were missing BMI on $10 \%$ of the patients in the cohort, but this is an unlikely source of bias since there was no difference between patients with and without BMI data in factors associated with BMI such as diabetes and hyperglycaemia. The AECC criteria are the most commonly used definition for ARDS. However, the body habitus of the obese presents special challenges in the determination of ARDS. Although additional analysis did not suggest that obese patients were more likely to be interpreted as

Table 5 Secondary outcomes in ARDS by weight

\begin{tabular}{|c|c|c|c|c|c|c|}
\hline Outcome & $\begin{array}{l}\text { Underweight } \\
(\mathrm{n}=22)\end{array}$ & $\begin{array}{l}\text { Normal } \\
(n=178)\end{array}$ & $\begin{array}{l}\text { Overweight } \\
(\mathrm{n}=186)\end{array}$ & $\begin{array}{l}\text { Obese } \\
(n=120)\end{array}$ & $\begin{array}{l}\text { Severely obese } \\
(\mathrm{n}=39)\end{array}$ & p Value \\
\hline ICU mortality & $9(45 \%)$ & $54(32 \%)$ & $56(31 \%)$ & $30(25 \%)$ & $13(33 \%)$ & 0.3 \\
\hline Ventilator-free days & $1.5(0-14)$ & $4.0(0-11)$ & $5.0(0-10)$ & $5.0(0-15)$ & $8.0(0-13)$ & 0.6 \\
\hline Hospital length of stay in days & $18(6-34)$ & $20(10-55)$ & $16(9-39)$ & $27(12-27)$ & $28(12-60)$ & 0.007 \\
\hline
\end{tabular}

Values are given as the median (25-75\%).

ARDS, acute respiratory distress syndrome; ICU, intensive care unit. 
having bilateral infiltrates, we cannot exclude the possibility that some of the obese patients who fulfil ARDS criteria may not have diffuse alveolar damage. However, universal lung biopsy of patients with ARDS is unrealistic. Data on volume status and fluid resuscitation were not available. Therefore, although weight was determined on ICU admission, we cannot exclude the possibility that fluids given prior to admission may have affected the BMI. As this is an observational study, we cannot exclude the possibility of unmeasured confounding. However, since this cohort was designed to examine development of ARDS, a large number of known predictors for development of ARDS were examined in this study. The population consisted of patients at risk for ALI/ARDS from common injuries such as sepsis, trauma, multiple transfusions and aspiration. The results may not be applicable to patients with less common risks for ARDS.

In conclusion, we report an association between BMI and development of ARDS, with increasing odds of ARDS with increasing obesity. Higher BMI and obesity were associated with longer lengths of stay but not ARDS mortality after adjusting for baseline clinical factors. With the increasing incidence of obesity, the results from this study suggest that critical care clinicians should be aware of the possibility of increased risk for ARDS in their obese and severely obese patients and they have implications regarding how such patients should be ventilated or managed.

Acknowledgements: The authors thank Wei-Ling Zhang, Kelly McCoy, Thomas McCabe, Christopher Schwartzenburg, Julia Shin, Hanae Fuji-Rios and Kezia Ellison for patient recruitment; Andrea Solomon, Andrea Shafer and Lia Shimada for research support; and Janna Frelich, Marcia Chertok, Sal Mucci, Richard Rivera for data management.

Funding: The present work is supported by research grants HL60197, HL084060 and HL086667 from NHLBI.

\section{Competing interests: None.}

Ethics approval: The Human Subjects Committees of the MGH, BIDMC and Harvard School of Public Health approved this study.

Provenance and peer review: Not commissioned; externally peer reviewed.

\section{REFERENCES}

1. Kopelman PG. Obesity as a medical problem. Nature 2000;404:635-43.

2. Flegal KM, Graubard BI, Williamson DF, et al. Excess deaths associated with underweight, overweight, and obesity. JAMA 2005;293:1861-7.

3. National Center for Health Statistics. Health, United States 2003. Hyattsville, MD: National Center for Health Statistics, 2003.

4. Newell MA, Bard MR, Goettler CE, et al. Body mass index and outcomes in critically injured blunt trauma patients: weighing the impact. J Am Coll Surg 2007;204:105661; discussion 62-4.

5. Joffe A, Wood K. Obesity in critical care. Curr Opin Anaesthesiol 2007:20:113-8.

6. Bercault N, Boulain T, Kuteifan K, et al. Obesity-related excess mortality rate in an adult intensive care unit: a risk-adjusted matched cohort study. Crit Care Med 2004;32:998-1003.

7. Yaegashi $\mathbf{M}$, Jean R, Zuriqat $\mathbf{M}$, et al. Outcome of morbid obesity in the intensive care unit. J Intensive Care Med 2005;20:147-54.
8. O'Brien JM Jr, Phillips GS, Ali NA, et al. Body mass index is independently associated with hospital mortality in mechanically ventilated adults with acute lung injury. Crit Care Med 2006;34:738-44.

9. Morris $\mathbf{A E}$, Stapleton RD, Rubenfeld GD, et al. The association between body mass index and clinical outcomes in acute lung injury. Chest 2007;131:342-8.

10. Akinnusi ME, Pineda LA, El Solh AA. Effect of obesity on intensive care morbidity and mortality: a meta-analysis. Crit Care Med 2008;36:151-8.

11. Rubenfeld GD, Caldwell E, Peabody E, et al. Incidence and outcomes of acute lung injury. N Engl J Med 2005;353:1685-93.

12. O'Brien JM Jr, Welsh CH, Fish $\mathrm{RH}$, et al. Excess body weight is not independently associated with outcome in mechanically ventilated patients with acute lung injury. Ann Intern Med 2004;140:338-45.

13. Gong MN, Thompson BT, Williams $\mathrm{P}$, et al. Clinical predictors of and mortality in acute respiratory distress syndrome: potential role of red cell transfusion. Crit Care Med 2005;33:1191-8.

14. Meade MO, Cook RJ, Guyatt GH, et al. Interobserver variation in interpreting chest radiographs for the diagnosis of acute respiratory distress syndrome. Am J Respir Crit Care Med 2000;161:85-90.

15. Schoenfeld DA, Bernard GR. Statistical evaluation of ventilator-free days as an efficacy measure in clinical trials of treatments for acute respiratory distress syndrome. Crit Care Med 2002;30:1772-7.

16. NHLBI. Executive summary of the clinical guidelines on the identification, evaluation, and treatment of overweight and obesity in adults. Arch Intern Med 1998:158:1855-67.

17. Tandon S, Batchelor A, Bullock R, et al. Peri-operative risk factors for acute lung injury after elective oesophagectomy. Br J Anaesth 2001;86:633-8.

18. Kuntz CL, Hadjiliadis D, Ahya VN, et al. Risk factors for early primary graft dysfunction after lung transplantation: a registry study. Clin Transplant 2009. Epub ahead of print.

19. Tremblay LN, Slutsky AS. Ventilator-induced lung injury: from the bench to the bedside. Intensive Care Med 2006;32:24-33

20. Jia X, Malhotra A, Saeed M, et al. Risk factors for ARDS in patients receiving mechanical ventilation for $>48 \mathrm{~h}$. Chest 2008:133:853-61.

21. Gajic 0, Frutos-Vivar F, Esteban A, et al. Ventilator settings as a risk factor for acute respiratory distress syndrome in mechanically ventilated patients. Intensive Care Med 2005;31:922-6.

22. Gajic 0, Dara SI, Mendez JL, et al. Ventilator-associated lung injury in patients without acute lung injury at the onset of mechanical ventilation. Crit Care Med 2004;32:1817-24.

23. Falagas ME, Kompoti M. Obesity and infection. Lancet Infect Dis 2006;6:438-46.

24. Centers for Disease Control and Prevention (CDC). Intensive-care patients with severe novel influenza A (H1N1) virus infection-Michigan, June 2009. WWMR Morb Mortal Wkly Rep 2009;58:1-4.

25. Frat JP, Gissot V, Ragot $\mathrm{S}$, et al. Impact of obesity in mechanically ventilated patients: a prospective study. Intensive Care Med 2008;34:1991-8.

26. Alam I, Lewis K, Stephens JW, et al. Obesity, metabolic syndrome and sleep apnoea: all pro-inflammatory states. Obes Rev 2006;8:119-27.

27. Vachharajani V. Influence of obesity on sepsis. Pathophysiology 2008;15:123-34

28. Bajwa EK, Yu CL, Gong MN, et al. Pre-B-cell colony-enhancing factor gene polymorphisms and risk of acute respiratory distress syndrome. Crit Care Med 2007;35:1290-5.

29. Ye SQ, Simon BA, Maloney JP, et al. Pre-B-cell colony-enhancing factor as a potential novel biomarker in acute lung injury. Am J Respir Crit Care Med 2005; 171:361-70.

30. Loffreda S, Yang SQ, Lin $\mathrm{HZ}$, et al. Leptin regulates proinflammatory immune responses. FASEB J 1998;12:57-65.

31. Bellmeyer A, Martino JM, Chandel NS, et al. Leptin resistance protects mice from hyperoxia-induced acute lung injury. Am J Respir Crit Care Med 2007;175:587-94.

32. Wosten-van Asperen RM, Lutter R, Haitsma JJ, et al. ACE mediates ventilatorinduced lung injury in rats via angiotensin II but not bradykinin. Eur Respir $J$ 2008;31:363-71.

33. Jacobson JR, Barnard JW, Grigoryev DN, et al. Simvastatin attenuates vascular leak and inflammation in murine inflammatory lung injury. Am J Physiol Lung Cell Mol Physiol 2005;288:L1026-32.

34. Pieracci FM, Hydo L, Pomp A, et al. The relationship between body mass index and postoperative mortality from critical illness. Obes Surg 2008;18:501-7.

35. Garrouste-Orgeas M, Troche G, Azoulay E, et al. Body mass index. An additional prognostic factor in ICU patients. Intensive Care Med 2004;30:437-43. 